\title{
Systemic lupus erythematosus-associated anetoderma and anti-phospholipid antibodies
}

\author{
M. Fernández-Galar, A. España and P. Lloret \\ Department of Dermatology, University Clinic of Navarra, Pamplona, Navarra, Spain
}

Correspondence: Agustín España, PO Box 4209, 31080 Pamplona, Navarra, Spain.

Tel.: +34 948 255400. Fax: +44 948 296500. E-mail: aespana@unav.es

\section{SUMMARY}

Anetoderma is characterized by a loss of normal elastic tissue that presents clinically as localized areas of wrinkled or flaccid skin. We describe the case of a 30-year-old woman with systemic lupus erythematosus-associated anetoderma and positive antiphospholipid antibodies. We discuss the possible role of these antibodies in the pathogenesis of anetoderma, and, when detected, the need to check for an associated anti-phospholipid syndrome in such patients.

\section{REPORT}

We present the case of a 30-year-old woman with a 9-year history of systemic lupus erythematosus (SLE). At initial diagnosis, the patient met four of the 11 criteria of the American Rheumatism Association's defining criteria for SLE: malar erythema, proteinuria in the context of membranous glomerulonephritis, positive anti-DNA antibodies (135 UVmL; normal range, 0-50 UVmL) and pleuropericardiac effusion. Investigations revealed negative anti-nuclear antibodies, complement C3 of $61 \mathrm{mg} / \mathrm{dL}$ (normal range, $80130 \mathrm{mg} / \mathrm{dL}$ ), C4 of $13.60 \mathrm{mg} / \mathrm{dL}$ (normal range, 15-30 mg/dL) and platelets of 195 (normal:150-350/pL). There was no history of spontaneous abortion, vascular thromboses, neurological disorders or heart valve defects.

The patient consulted our Department with a 6-month history of asymptomatic 'reddish' lesions on the trunk and limbs. Physical examination revealed raised erythematous plaques on the trunk and limbs ranging from 1 to $4 \mathrm{~cm}$ in diameter. She also had other pink lesions of a similar size, which were raised and soft on palpation, on the trunk and arms (Fig. 1a and b). A skin biopsy specimen of the reddish plaques showed an epidermis with preservation of the basal layer and a perivascular lymphomonocytic infiltrate. There were no thromboses or signs of vasculitis. In the pink plaques, the lymphomonocytic infiltrate was less prominent. Direct immunofluorescence was performed on both types of lesion. Similar findings were observed: subepidermal linear deposits of IgA and granular deposits of IgG, IgM, C3 and C1q. In the blood vessels there were also IgM and C3 deposits (Fig. 2a). Orcein staining revealed loss of elastic fibres which was more evident in the softer plaque specimens (Fig. 2b). Despite the immunofluorescence findings there was no clinicopathological evidence for a subepidermal immunobullous disorder such as linear IgA disease or bullous pemphigoid. Neither was there any evidence of bullous SLE. Laboratory tests showed 
positive anti-cardiolipin antibodies and negative lupus anticoagulant. A diagnosis of SLE-associated anetoderma was made. The patient was treated with oral corticosteroids (deflazacort $12 \mathrm{mg} /$ day), but without significant changes in the skin plaques.

Anetoderma is an unusual disease of unknown aetiology. In its primary form, hormonal factors have been implicated, owing to its association with pregnancy and illnesses such as Addison's disease. ${ }^{1}$ In other cases, an association with anti-Borrelia antibodies has been described. ${ }^{2}$ Stephansson et al. examined antiBorrelia antibodies in 14 patients but only one patient had an elevated IgM titre. However, three other patients had slightly elevated anti-Borrelia antibodies, although none of them had symptoms associated with Borrelia infection. Aside from endocrine or infections hypothesis, there has been increasing evidence for an immunological basis to anetoderma. Such ideas are supported by findings of immunoglobulin deposition on direct immunofluorescence (DIF) on anetoderma lesions, as well as by the known association of anetoderma with various autoimmune diseases. Hodak et al. ${ }^{3}$ reported six patients in whom DIF was positive at both the dermo-epidermal junction and within dermal blood vessels. Bergman et al. ${ }^{4}$ also described a subepidermal linear deposit similar to that noted in our patient. Furthermore, in some of the reported cases, immunoglobulin deposition around dermal collagen and elastic fibres was a feature.

To our knowledge, the literature contains only 13 cases of patients with anetoderma associated with SLE. ${ }^{5}$ A key point has been that the association is not so much with lupus erythematosus as with the presence of antiphospholipid antibodies (APA). ${ }^{6}$ Stephansson et al. ${ }^{2}$ observed that in a series of SLE patients, $15 \%$ of those with positive APA developed anetoderma, whereas none of those without these antibodies developed this skin condition. Similarly, patients with anetoderma have been described who did not develop lupus erythematosus, whereas they did have APA. Anetoderma might even be regarded as one further skin manifestation of anti-phospholipid syndrome, although not all patients with APA and anetoderma will develop this syndrome.

What are the possible mechanisms through which these antibodies produce anetoderma? The findings in some skin biopsies of microthrombosis ${ }^{2,5,6}$ in patients with anetoderma and associated APA, have led some authors to consider that ischaemia of dermal tissues may trigger degeneration of elastic tissue. ${ }^{7,8}$ This pathological process may also be relevant in patients with lupus-related nephropathy, as renal function tends to deteriorate more quickly in APA-positive patients. ${ }^{9}$ It has also been suggested that the APA bind directly to the elastic fibres because of the presence of an antigen epitope that is phospholipid related, possibly apolipoprotein $\mathrm{H}^{8}$ On the other hand, Skelton et al. ${ }^{10}$ studied anetoderma in patients with HIV infection, and described how the anticardiolipin antibodies might act by altering the mechanism of the inhibitors of certain dermal proteinases thereby favouring the destruction of elastic fibres. These authors, and others, maintain that the elastases from the inflammatory cells are responsible for the damage to the elastic fibres. ${ }^{2,8}$ Finally, the importance of disrupting inhibitors of proteolysis is highlighted in cases of patients with an alpha-1-anti-trypsin deficiency who also develop anetoderma. ${ }^{2}$

In summary, in spite of the need to examine more cases to conclude if there is a significant association, we think it appropriate for all patients with anetoderma to be examined for autoimmune diseases and APAs in particular, as well as being followed and screened for the emergence of anti-phospholipid syndrome. 


\section{REFERENTES}

1. Shames BS, Fretzin D. Disorders of collagen, elastin, and ground substance. In: Moschella SL, Hurley HJ, eds. Dermatology. Pennsylvania: W.B. Saunders Company, 1992.

2. Stephansson EA, Niemi K-M. Antiphospholipid antibodies and anetoderma: Are they associated? Dermatology 1995; 191: 202-9.

3. Hodak E, Shamai-Lubovitz O, David $\mathrm{M}$ et al. Immunologic abnormalities associated with primary anetoderma. Arch Dermatol 1992; 128: 799-803.

4. Bergman R, Friedman-Birnbaum R, Hazaz B et al. An immunofluorescence study of primary anetoderma. Clin Exp Dermatol 1990; 15: 124-30.

5. Montilla C, Alarcón Segovia D. Anetoderma in systemic lupus erytematosus: relationship to antiphospholipid antibodies. Lupus 2000; 9: 545-7.

6. Disdier P, Harlé J-R, Andrac R et al. Primary anetoderma associated with the antiphospholipid syndrome. J Am Acad Dermatol 1994; 30: 133-4.

7. Gibson GE, Daniel Su WP, Pittelkow MR. Antiphospholipid syndrome and the skin. JAm AcadDermatol 1997; 36:970-82.

8. RomaníJ, Pérez F, Llobet $\mathrm{M}$ et al. Anetodermia asociada a anticuerpos antifosfólipidos: caso clínico y revisión de la literatura. JEADV 2001; 15: 1758.

9. Perdiguero $\mathrm{M}$, Boronat $\mathrm{M}$, Marco $\mathrm{P}$ et al. The role of antiphospholipid antibodies in lupus nephropathy. Nephron 1995; 71: 35-9.

10. Lindstrom J, Smith KJ, Skelton HG et al. Increased anticardiolipin antibodies associated with the development of anetoderma in HIV-1 disease. Int J Dermatol 1995; 34: 408-15. 

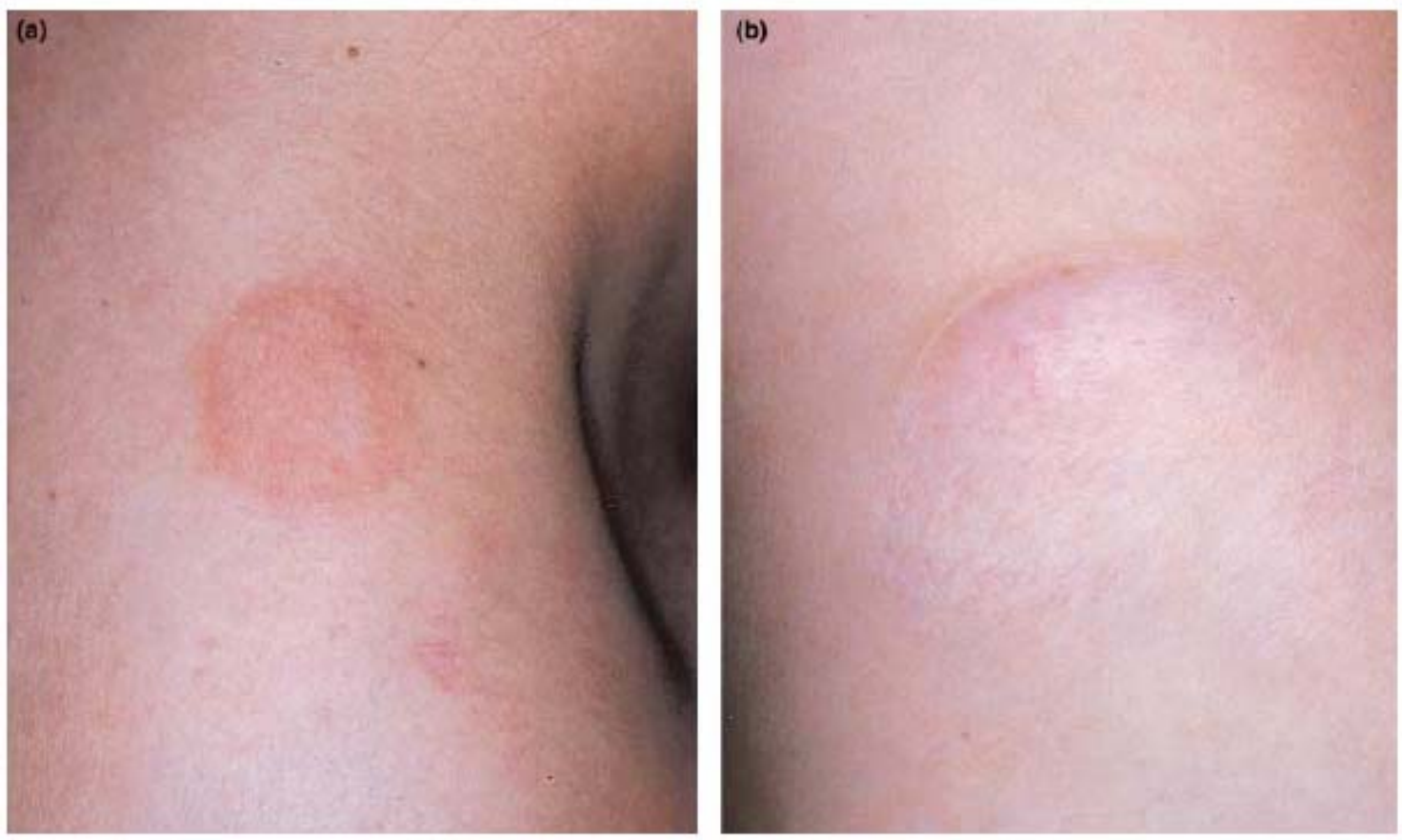

Figure 1. (a) Raised erythematous lesion on the neck. (b) Saccular anetoderma lesion on the arm. 


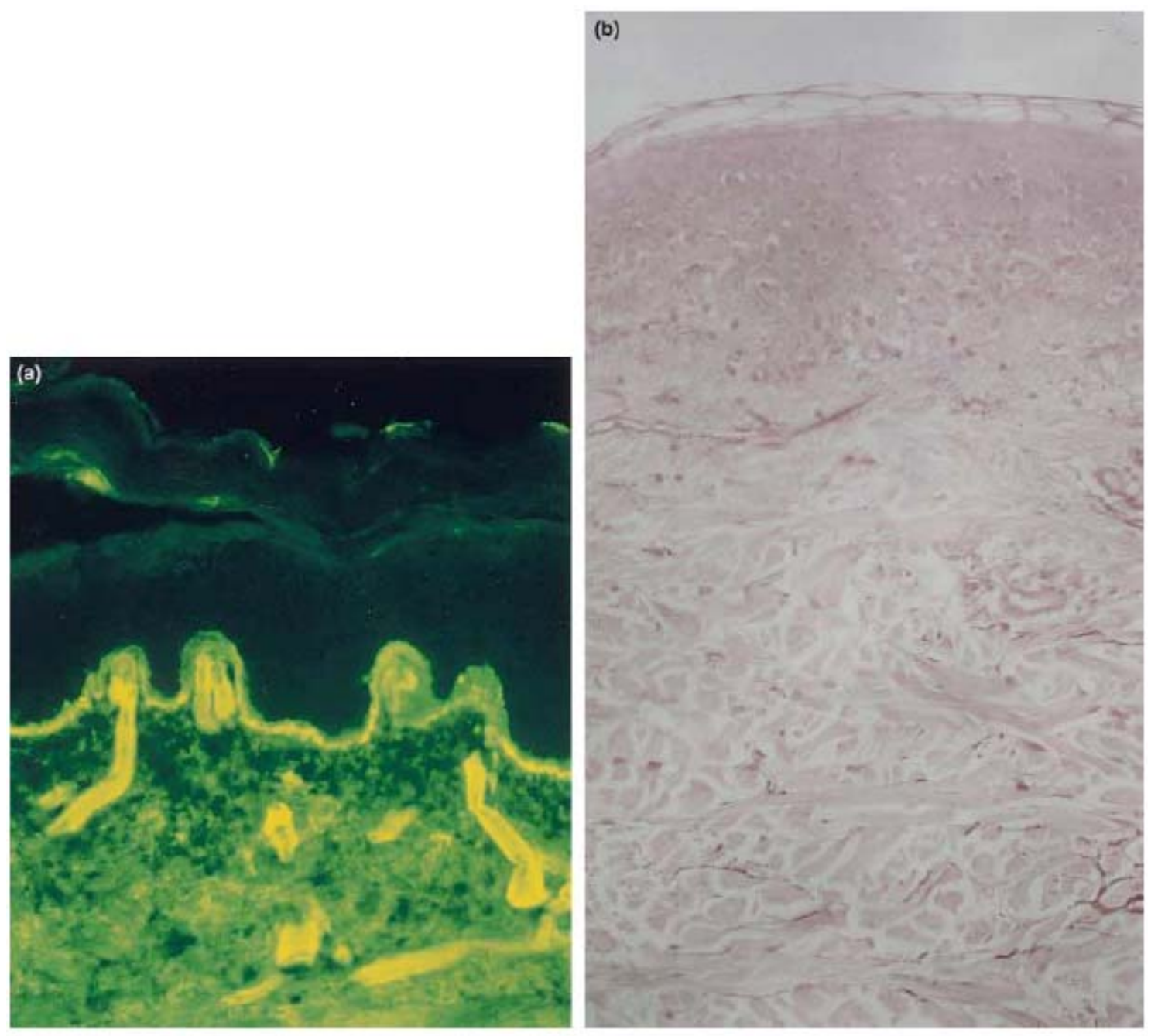

Figure 2. (a) Direct immunofluorescence analysis revealed subepidermal linear deposits of IgA. In the blood vessels there was also IgM and C3 deposition. (b) Orcein staining, demonstrating few elastic fibres, consistent with anetoderma. 